\title{
DAPSONE SYNDROME
}

\author{
(A Case Report)
}

\author{
Lt Col S RAMACHANDRA*, Col AB PRADHAN+, \\ Brig RS PAHWA\#
}

MJAFI 1995; 51 : 220-221

KEY WORDS : Dapsone; Drug hypersensitivity.

\section{Introduction}

D apsone syndrome is an uncommon hypersensitivity reaction to diamino diphenyl sulfone. This syndrome is characterised by high fever, maculopapular rashes, hepatitis, lymphadenopathy and lymphocytosis. It generally appears within first 6 weeks of treatment [1]. A case of borderline tuberculoid leprosy who developed this syndrome is reported.

\section{CASE REPORT}

A 21-year-old male patient was admitted with a solitary hypopigmented, anaesthetic patch with broken margins and satellite lesions. A clinical diagnosis of leprosy, borderline tuberculoid, was made and confirmed histopathologically. He was put on multidrug therapy consisting of daily dapsone and monthly rifampicin. On 27th day of therapy patient developed high fever, mild sorethroat and anorexia. He was given symptomatic treatment. But fever persisted and he developed icterus and mild tender hepatomegaly on 31st day. Serum bilirubin (direct positive) rose to $2 \mathrm{mg} / \mathrm{dL}$ however SGOT (12 IU/litre) and SGPT (10 IU/litre) were within normal limits and urine for bile salts and bile pigments was negative. As sore throat persisted he was given a course of ampicillin. After 2 days, he developed itchy maculopapular rashes over face, trunk and extremities. Suspecting ampicillin to be the offender, the drug was stopped immediately. But patient continued to run high grade fever (104-105 $\mathrm{F}$ ) and dermatitis progressed to exfoliation. He also developed swelling of face, lips and ulceration in the mouth (Fig). There was generalised, nontender, firm, discrete lymphadenopathy involving cervical, axillary and inguinal groups. Blood count showed'lymphocytosis (50\%).

Dapsone was stopped on 11th day of the acute illness and systemic corticosteroid was added (Tab Betnelan 2 tablets thrice a day). He was also given intravenous fluid and other supportive therapy. The patient started show- ing gradual improvement within a week of this therapy. Temperature gradually touched normal, hepatitis and dermatitis regressed, mouth ulceration and lymphadenopathy started subsiding. Gradually blood count and biochemical parameters likke serum bilirubin came back to normal. Later systemic corticosteroid was tapered off and he became symptom free on 33rd day of the acute illness.

To confirm the clinical diagnosis, suspected drugs like ampicillin and dapsone were reintroduced one by one. He did not develop adverse reaction to ampicillin. After a week, a challenging dose of dapsone (25 $\mathrm{mg}$ ) was given. He developed itching and maculopapular rashes within 2 hours and also had fever (101-102 ${ }^{\circ} \mathrm{F}$ ) lasting for one day. The symptoms were controlled with antihistamines and a short course of systemic corticosteroid.

\section{Discussion}

Allday and Barnes [1] were the first to

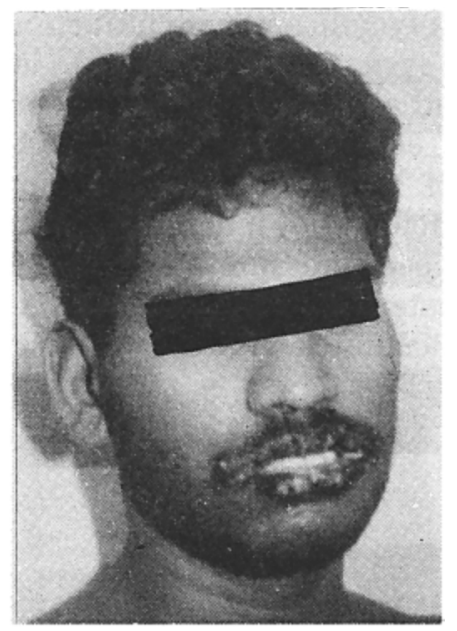

Eig. : Swelling and ulceration of lips in dapsone syndrome.

*Classified Specialist (Derm \& Ven); +Senior Adviser (Medicine); \#Commandant; 167 Military Hospital, C/O 56 APO. 
describe the term dapsone syndrome. Dapsone is the drug of choice in treatment of all types of leprosy and it is generally well tolerated by the patients. Untoward effects noted with this drug are methaemoglobinaemia, haemolytic anaemia, agranulocytosis, dermatitis, hepatitis, neuritis and very rarely renal papillary necrosis [2]. Dapsone syndrome is one of the rare hypersensitivity reactions. Leucocytosis, abnormal erythrocytes with anemia [3], increase in number of eosinophils also have been reported, associated with this syndrome [4]. In our case, though serum transaminase levels were found normal, serum bilirubin was high indicating involvement of liver. The patient manifested full form of syndrome and dapsone provocative test confirmed clinical diagnosis.

\section{REFERENCES}

1. Allday EJ, Barnes J. Toxic effects of DDS in treatment of leprosy. Lancet 1951; $2: 205-6$.

2. Graham WR. Adverse effects of Dapsone. Int J Dermatol 1975; $14: 495-500$

3. Tomeck SK, Catalano CJ. Dapsone hypersensitivity, the sulfone syndrome revised. Arch Dermatol 1981; $117: 38-9$.

4. Milikan LE, Harrel ER, Arbor A. Drug reaction to sulfones. Arch Dermatol 1970; $102: 220-4$. 